\title{
New Rabbit Erythrocyte Specific Mycelial Lectins from Fusarium sp. with Complex Saccharide Specificity
}

\author{
Ram Sarup Singh", Shivani Rani Thakur \\ Carbohydrate and Protein Biotechnology Laboratory, Department of Biotechnology, Punjabi University, Patiala 147 002, Punjab, India.
}

\begin{tabular}{|c|c|}
\hline ARTICLE INFO & ABSTRACT \\
\hline $\begin{array}{l}\text { Article history: } \\
\text { Received on: May 17, } 2018 \\
\text { Accepted on: June 27, } 2018 \\
\text { Available online: March 05, } 2019\end{array}$ & $\begin{array}{l}\text { Eight Fusarium sp. namely, F. acutatum, F. globosum, F. graminearum, F. lactis, F. nivale, F. proliferatum, } F \text {. } \\
\text { pseudoanthophilum and } F \text {. robustum were screened for the presence of lectins by hemagglutination activity } \\
\text { using human ABO, porcine, ovine, goat and rabbit erythrocytes. Mycelial extracts of all the fungal cultures } \\
\text { except } F \text {. graminearum displayed unique lectin activity with only rabbit erythrocytes. Enzymatic treatment of } \\
\text { rabbit erythrocytes with neuraminidase has significantly enhanced the titre of all the lectin-positive extracts }\end{array}$ \\
\hline $\begin{array}{l}\text { Key words: Fusarium, mycelial } \\
\text { lectins, hemagglutination titre, } \\
\text { erythrocyte, glycan, saccharide, } \\
\text { sialic acid. }\end{array}$ & $\begin{array}{l}\text { of fungal cultures. In contrast, most of the lectins showed a decline in lectin activity with protease treated } \\
\text { rabbit erythrocytes. Saccharide specificity studies have shown that majority of the lectins are inhibitory towards } \\
O \text {-acetyl sialic acids. None of the lectins from Fusarium sp. were inhibited by dextran, meso-inositol, and } \\
N \text {-acetyl-D-glucosamine. Most of the fungal cultures displayed highest hemagglutination activity during the } \\
10^{\text {th }} \text { day of growth in broth cultures. The unique saccharide specificity of Fusarium sp. lectins can be used for } \\
\text { elucidating their clinical role in glycobiology research. }\end{array}$ \\
\hline
\end{tabular}

\section{INTRODUCTION}

Lectins are glycan-binding proteins (GBPs) that are very judicious in recognizing glycan epitopes which are expressed on free carbohydrates or glycoproteins. Since their discovery, lectins are identified in all the branches of an evolutionary tree, from bacteria, fungi, viruses, algae, plants, and animals, etc. [1]. Thus, the presence of lectins in all living organisms insight an old evolutionary onset, triggering an expanding interest in Lectinology. Owing to their capability of discriminating carbohydrate structures, lectins can not only be used as valuable biochemical reagents in numerous fields but also as a potent candidate for biomedical research $[2,3,4]$. The sugar-binding ability of lectins has made them a basic tool in glycomic studies. Lectins recognize carbohydrates through metal coordination, hydrogen bonding, hydrophobic interactions and van der-Waal forces. Furthermore, a profound understanding of lectin-carbohydrate association opens tremendous and unexplored potential outcomes in numerous territories of biology and medicine [5]. In cancer research, lectins are thought to be pioneer supporters of tumor cell localization, cell adhesion, and recognition, signal transduction across membranes, mitogen incitement, cytotoxicity and apoptosis $[6,7,8,9]$. Lectins have also been

"Corresponding Author

Ram Sarup Singh, Carbohydrate and Protein Biotechnology Laboratory, Department of Biotechnology, Punjabi University, Patiala, Punjab, India.E-mail:rssingh11@lycos.com recommended as an effective tool for screening of potential cancer biomarkers [10]. The role of lectin microarrays in cancer diagnosis is well established [11].

Due to their ubiquity in nature, lectins play distinct roles in plants, animals, fungi, bacteria, algae, and viruses etc. The role of lichen lectins in symbiosis is well established [12]. Amongst microbes lectins are widely reported from algae [2,13], mushrooms $[9,14]$, yeast $[15]$, microfungi $[1,16]$, cyanobacteria $[17,18]$, protozoa $[19,20]$, etc. Microfungal lectins have gained much impetus due to their distinctive saccharide specificities. Our group has revealed a high incidence of lectins from microfungi including Aspergillus sp. [21,22,23] and Penicillium sp. $[24,25,26]$. Lectins from aspergilli $[27,28,29,30]$ and penicilli [31] are reported potent mitogenic. Immunomodulatory potential of lectins from Aspergillus sp. is well established [32,33,34].

Fusarium species are ubiquitous and are present in soil, air and on plants. It is a well-known plant pathogen and sometimes it also causes various infections in humans. In earlier studies, our group has reported many lectin-positive Fusarium species $[35,36]$. The present work is an augmentation of our earlier work to investigate lectin activity in new Fusarium sp., which has not been investigated previously. The lectins were investigated for their hemagglutination activity and hapten inhibition studies. The present research would provide useful information for cataloging the lectins from Fusarium sp. and to investigate their clinical role in glycobiology research. 


\section{MATERIALS AND METHODS}

\subsection{Fungal Cultures}

Eight strains of Fusarium sp. were procured from Microbial Type Culture Collection, Institute of Microbial Technology, Chandigarh, India. $F$. acutatum MTCC 9949, $F$. globosum MTCC 9953, $F$. graminearum MTCC 1893, F. lactis MTCC 9944, F. nivale MTCC 7587, F. proliferatum MTCC 9635, F. pseudoanthophilum MTCC 9955 and F. robustum MTCC 9908 were maintained on PDA slants containing (\%): potato extract 20.0, dextrose 2.0, agar 3.0 and $\mathrm{pH}$ of the medium was adjusted to 5.6. The subculturing of all the fungal strains was carried out at fortnight intervals. The active culture agar slopes were stored at $4^{\circ} \mathrm{C}$, until further use.

\subsection{Cultivation of Fungal Strains}

All the fungal strains were grown by inoculating one culture disc ( 5 $\mathrm{mm}$ diameter) into Erlenmeyer flasks $(250 \mathrm{~mL})$ containing $100 \mathrm{~mL}$ of the same sterile medium used for their maintenance except agar. The inoculated flasks were kept at $25^{\circ} \mathrm{C}$ in a BOD incubator (NSW256, Narang Scientific Works, India) for 10 days (unless otherwise specified), under stationary condition. Likewise, the cultures were also cultivated on agar plates of the same medium and kept under similar conditions.

\subsection{Preparation of Lectin Extract}

Fungal biomass of each strain was obtained by filtration of broth cultures and washed thoroughly with glass-distilled water followed by phosphate buffered saline (0.1 M, pH 7.2). Then, it was pressed dry in many folds of ordinary filter paper. The fungal extract was prepared in phosphate buffer saline $(1: 1.5 \mathrm{w} / \mathrm{v})$ and assayed for intracellular lectin activity as described previously [21]. Mycelium free broth was also checked for extracellular lectin activity. Whereas, the mycelia grown on agar plates were scraped free of agar and processed similarly for the preparation of lectin extract to determine the intracellular lectin activity.

\subsection{Lectin Activity from Conidia}

Briefly, conidia were obtained by scraping the mycelia of 10-day old agar plate cultures. The mycelia were suspended in a test tube containing PBS (0.1 M, pH 7.2) and glass beads. Then, the test tube was vortexed at room temperature for $10 \mathrm{~min}$. The suspension containing conidia was decanted and centrifuged $(1500 \times \mathrm{g})$ for $5 \mathrm{~min}$ at $4^{\circ} \mathrm{C}$. The pellet was resuspended in PBS and absorbance was adjusted to 0.6 (approximately $10^{8}$ conidia $/ \mathrm{mL}$ ). Absorbance was measured in a square Quartz cuvette $(12.5 \mathrm{~mm} \mathrm{~W} \times 49 \mathrm{~mm} \mathrm{H} \times 12.5 \mathrm{~mm} \mathrm{D})$ at $620 \mathrm{~nm}$ using a spectrophotometer (Pharmaspec UV-1700, Shimadzu, Japan). Aliquots of conidial suspensions $(2 \mathrm{~mL})$ were subjected to sonication for $5 \mathrm{~min}$ at an acoustic power of $200 \mathrm{~W}$ with $30 \mathrm{~s}$ pulse on and off each in an ice bath using an ultrasonicator (VCX 750, Sonics \& Materials Inc., USA). Sonicated conidial suspension was centrifuged $\left(8000 \times \mathrm{g}, 4^{\circ} \mathrm{C}, 10 \mathrm{~min}\right)$ in a refrigerated centrifuge (REMI CPR-30 PLUS) and supernatant thus obtained was analyzed for lectin activity.

\subsection{Lectin Activity vs. Culture Age}

All the lectin-positive cultures were cultivated in Erlenmeyer flasks $(250 \mathrm{~mL})$ containing $100 \mathrm{~mL}$ of the respective medium used for their maintenance except agar and inoculated with one culture disc $(5 \mathrm{~mm})$. The inoculated flasks were incubated at $25^{\circ} \mathrm{C}$, under a stationary condition in a BOD incubator (NSW-152, Narang Scientific Works,
India) for 5-12 days. The mycelium recovered after $24 \mathrm{~h}$ intervals were homogenized in PBS $(1: 1.5, \mathrm{w} / \mathrm{v})$, and then ground in pestle and mortar for 30 min with acidified river sand (40-200 mesh EP, SD Fine-Chem Ltd., India). Invariably, the same amount of biomass was taken for each of the cultures at regular time intervals to determine the relative hemagglutination titre as a function of culture age.

\subsection{Erythrocyte Preparation}

Human volunteers and animal's fresh blood samples were drawn in the ratio of 1:2 in Alsever's solution ( $\mathrm{pH}$ 6.1) containing (\%): sodium chloride 0.42 , glucose 2.05 and sodium citrate 0.8 . Blood from human volunteers was withdrawn from the antecubital vein. Goat, sheep and pig blood was procured from a local butchery of Patiala. Rabbit (New Zealand white) blood was withdrawn from a marginal vein on the lateral side of ear pinna using a syringe fitted with 22 gauge needle. Erythrocyte suspension $(2 \%, \mathrm{v} / \mathrm{v})$ was prepared in PBS $(0.1 \mathrm{M}, \mathrm{pH} 7.2)$ and used to ascertain lectin activity as described previously [21]. The suspension was stored at $4^{\circ} \mathrm{C}$, until further use.

\subsection{Enzymatic Modification of Rabbit Erythrocytes}

For enzymatic modification of erythrocytes, $1 \mathrm{~mL}$ of rabbit erythrocyte suspension $(10 \%, \mathrm{v} / \mathrm{v})$ was mixed with an equal volume of neuraminidase $(0.2 \mathrm{IU} / \mathrm{mL}$, Sigma Pvt. Ltd., USA) or protease $(2 \mathrm{mg} /$ $\mathrm{mL}$, Biocompare ICN, USA) and kept at $37^{\circ} \mathrm{C}$ for $60 \mathrm{~min}$ as described previously [24]. The reaction was ceased by adding an excess of PBS (0.1 M, pH 7.2) and centrifuged at $400 \times \mathrm{g}$ for $5 \mathrm{~min}$ at $4^{\circ} \mathrm{C}$. To remove traces of enzyme, the pellet was washed thrice with PBS and resuspended in PBS to make a final concentration of $2 \%(\mathrm{v} / \mathrm{v})$. Lectin activity was detected using enzymatically modified erythrocytes.

\subsection{Hemagglutination Activity Assay}

Hemagglutination activity (lectin activity) assay was performed using human $\mathrm{ABO}$, ovine, goat, porcine and rabbit erythrocytes as described previously by [24]. Agglutination assays were performed in 96-well U-bottom microtitre plates (Tarsons Products Pvt. Ltd., India) by adding $20 \mu \mathrm{L}(2 \%, \mathrm{v} / \mathrm{v})$ of erythrocyte suspension (enzyme treated/untreated) to $20 \mu \mathrm{L}$ of serially diluted lectin in PBS. Microtitre plates were kept at room temperature for $30 \mathrm{~min}$, stabilized at $4^{\circ} \mathrm{C}$ for 1-2 $\mathrm{h}$. The intensity of activity was observed visually, based on hemagglutination pattern in microtitre plates. The mat formation shows the presence of lectin activity, while button formation at the bottom of cavity indicates the absence of lectin activity. Lectin activity is expressed as a hemagglutination titre, which is inverse of the highest dilution capable of visible agglutination. All the experiments were carried out in triplicates.

\subsection{Saccharide Specificity Assay}

Saccharide specificity of lectins was determined by hemagglutination inhibition assay. The inhibition assay was performed against a panel of carbohydrates as described earlier by [21]. To $20 \mu \mathrm{L}$ of appropriately diluted lectin (twice the lowest concentration capable of visible agglutination), an equal volume of sugar solution to be tested for inhibition was added in U-bottom microtitre plates. After $1 \mathrm{~h}$ of incubation at room temperature, $40 \mu \mathrm{L}$ of $2 \%(\mathrm{v} / \mathrm{v})$ erythrocyte suspension was added to each well and plates were further kept for $30 \mathrm{~min}$ at room temperature. A positive control was run containing $20 \mu \mathrm{L}$ PBS rather than lectin extract and the negative control contained $20 \mu \mathrm{L}$ PBS instead of sugar solution. The plates were stabilized at $4^{\circ} \mathrm{C}$ for $2-3 \mathrm{~h}$. Formation of a button in the presence 
of sugar indicated the inhibition of lectin activity, i.e. a positive reaction, while mat formation indicated no inhibition by the sugar. Minimum inhibitory concentration (MIC) of each sugar was analyzed by serial double dilution of the sugar solution. MIC is defined as the lowest concentration of sugar capable of complete inhibition of agglutination. The tested carbohydrates (Sigma-Aldrich Co., USA) included monosaccharides: D-arabinose, L-arabinose, L-fucose, D-fructose, D-galactose, D-mannose, D-mannitol, L-rhamnose, D-ribose, D-xylose and D-glucose; disaccharides: D-lactose, D-maltose, D-melibiose, D-sucrose and D-trehalose dehydrate; trisaccharides: maltotriose and D-raffinose; polysaccharides: dextran, starch, pullulan and inulin; sugar derivatives: 2-deoxy- D-glucose, 2-deoxy-D-ribose, D-glucosamine hydrochloride, D-galactosamine hydrochloride, D-glucuronic acid, D-galacturonic acid, N-acetyl-Dgalactosamine, N-acetyl-D-glucosamine, N-acetyl-neuraminic acid, inositol and mesoinositol; glycoproteins: fetuin, asialofetuin, porcine stomach mucin, chondroitin-6-sulphate, $\gamma$-globulin, thiogalactoside and bovine submaxillary mucin. Simple sugars and their derivatives were tested at a concentration of $100 \mathrm{mM}$, whereas, glycoproteins and polysaccharides were tested at a final concentration of $1 \mathrm{mg} / \mathrm{mL}$. The minimal sugar inhibition was assessed by the ability to completely inhibit hemagglutination activity. All the experiments were performed in triplicates.

\subsection{Statement of Ethics}

Institutional ethics committee for animals (Permit No. 107/99/ CPCSEA/2014-28) and humans (Permit No. 139/DLS/HG) has approved all experimental protocols.

\section{RESULTS AND DISCUSSION}

\subsection{Lectin Activity from Fusarium sp.}

Seven Fusarium species namely, F. acutatum, F. globosum, F. lactis, $F$. nivale, $F$. proliferatum, $F$. pseudoanthophilum and $F$. robustum were found lectin-positive (Table 1). Mycelial extracts from these seven species agglutinated only rabbit erythrocytes and showed no agglutination with a goat, ovine, porcine and human $\mathrm{ABO}$ erythrocytes. In a recent report, the majority of the Fusarium sp. lectins have agglutinated only rabbit erythrocytes [36] which corroborate our findings. Lectins from Fusarium sp. has also been reported sensitive to the horse, chick, rabbit and human ABO erythrocytes [37] as well as to pig, sheep and goat erythrocytes [35]. F. solani lectin exhibited erythro-agglutination only with pronase and neuraminidase treated human erythrocytes [38]. Fusarium sp. lectins agglutination only with rabbit erythrocytes accounts for the presence of primary epitope determinant for 9-O-acetyl neuraminic acid, which is present on the surface glycoconjugates of rabbit erythrocytes [39,40]. Additionally, lectins from Fusarium sp. did not show any interaction with N-acetyl neuraminic acid which justifies the failure of lectins to agglutinate human A, O, sheep, and goat erythrocytes [36].

None of the species demonstrated extracellular lectin activity in mycelium free-culture broth. Intracellular mycelial lectin activity has been previously reported from Fusarium oxysporum, Fusarium moniliforme [41] and Fusarium sp. [38,35,36]. Lectins from mycelial extracts of F. globosum, F. lactis, F. pseudoanthophilum and $F$. robustum, grown on solidified medium showed two-times low hemagglutination activity (titre $4,64,8,16$, respectively) than their corresponding broth cultures (Table 2). Thus, these findings of lower lectin titre from cultures grown on agar plates substantiate our previous reports on lectins from Fusarium sp. [35], Aspergillus sp.
[21,23], and Penicillium sp. [24,26]. None of the conidial extracts from Fusarium sp. indicated erythro-agglutination advocating that the lectin is confined exclusively in the mycelia. Similar lectin activity has been accounted from resting conidia and mycelia of Aspergillus fumigatus [42]. Likewise, conidial lectin activity has also been reported from Chrysosporium keratinophilum and Anixiopsis stercoraria [43].

Table 1: Screening of Fusarium sp. for lectin activity with rabbit erythrocytes.

\begin{tabular}{lcc}
\multicolumn{1}{c}{ Fungal culture } & \multicolumn{2}{c}{ Lectin activity (Titre) } \\
& After 7 days & After 10 days \\
Fusarium acutatum MTCC 9949 & 32 & 32 \\
Fusarium globosum MTCC 9953 & 8 & 8 \\
Fusarium graminearum MTCC 1893 & 0 & 0 \\
Fusarium lactis MTCC 9944 & 16 & 128 \\
Fusarium nivale MTCC 7587 & 16 & 32 \\
Fusarium proliferatum MTCC 9635 & 0 & 2 \\
Fusarium pseudoanthophilum MTCC 9955 & 0 & 16 \\
Fusarium robustum MTCC 9947 & 4 & 32 \\
\hline
\end{tabular}

Table 2: Comparative lectin activity of Fusarium sp. on agar plates and in liquid medium after 10 days of cultivation.

\begin{tabular}{lcc}
\multicolumn{1}{c}{ Fungal culture } & \multicolumn{2}{c}{ Lectin activity (Titre) } \\
& Solidified medium & Submerged cultivation \\
Fusarium acutatum & 32 & 32 \\
Fusarium globosum & 4 & 8 \\
Fusarium lactis & 64 & 128 \\
Fusarium nivale & 32 & 32 \\
Fusarium proliferatum & 2 & 2 \\
Fusarium pseudoanthophilum & 8 & 16 \\
Fusarium robustum & 16 & 32 \\
\hline
\end{tabular}

aLectin activity with rabbit erythrocytes.

\subsection{Saccharide Specificity}

Lectin activity of most of the Fusarium sp. was found inhibitory to D-ribose, L-rhamnose, D-glucose, D-mannose, D-arabinose, D-mannitol, D-sucrose, D-maltose, D-lactose, D-trehalose-dihydrate and 2-Deoxy-D-glucose (Table 3). Amongst the monosaccharides examined, lectins from $F$. globosum, $F$. proliferatum, and $F$. pseudoanthophilum were inhibited by D-ribose and L-rhamnose. $F$. globusum and F. pseudoanthophilum lectins demonstrated an affinity for D-arabinose, though lectin from $F$. proliferatum could recognize D-and L-isomers of arabinose. Such lectins can serve as a valuable tool for investigating lectin-carbohydrate interactions and as a vector to determine the sugar specificity [44].

Lectins from $F$. proliferatum and $F$. pseudoanthophilum were inhibited by L-fucose. Fucose-specific lectins have been reported from Fusarium sp. [35,36], Aspergillus sp. [21,23], and Penicillium sp. [26]. Mannose specificity was exhibited by $F$. proliferatum lectin. Mannose-binding lectins (MBL) perceive fucose, terminal mannose and $\mathrm{N}$-acetylglucosamine which are available in plenitude in microbial glycans, giving a blueprint for recognition and neutralization of pathogens of the innate immune system [45]. Lectin activity of $F$. globosum, $F$. proliferatum, $F$. nivale and $F$. pseudoanthophilium with a MIC of $6.25 \mathrm{mM}, 3.125 \mathrm{mM}, 25 \mathrm{mM}$ and $3.125 \mathrm{mM}$ respectively, was inhibited by D-fructose. Lectins showcasing fructose specificity 
have also been reported from Fusarium sp. [35,36], Aspergillus sp. [23] and Penicillium sp. [46,26]. Lectin activity of $F$. globosum and $F$. proliferatum was inhibited by galactose, whereas $F$. nivale lectin suppressed the activity of galactose-containing sugar-lactose. $F$. moniliforme and $F$. oxysoporum lectins displayed potent inhibition against $\mathrm{D}$-galactose and $\mathrm{N}$-acetylglucosamine [46]. None of the
Fusarium sp. lectins except, F. globosum and F. pseudoanthophilium showed a strong affinity for the trisaccharides (D-raffinose and maltotriose). Out of various polysaccharides tested inulin, pullulan and starch displayed strong affinity towards lectins from $F$. nivale and F. proliferatum. Polysaccharide inhibiting lectin activities of Fusarium sp. have also been reported in a previous report [35].

Table 3: Carbohydrate inhibition profile of lectins from Fusarium sp.

\begin{tabular}{|c|c|c|c|c|c|c|c|}
\hline \multirow{2}{*}{ Carbohydrate/Glycoprotein } & \multicolumn{7}{|c|}{ Minimum inhibitory concentration (MIC) } \\
\hline & F. acutatum & F. globosum & F. lactis & F. nivale & F. proliferatum & F. pseudoanthophilum & F. robustum \\
\hline D-ribose & - & $>25 \mathrm{mM}$ & - & - & $>25 \mathrm{mM}$ & $>3.125 \mathrm{mM}$ & - \\
\hline L-rhamnose & - & $>12.5 \mathrm{mM}$ & - & - & $>3.125 \mathrm{mM}$ & $>12.5 \mathrm{mM}$ & - \\
\hline Xylose & - & - & - & - & - & $>6.25 \mathrm{mM}$ & - \\
\hline L-fucose & - & - & - & - & $>3.125 \mathrm{mM}$ & $>3.125 \mathrm{mM}$ & - \\
\hline D-glucose & $>3.125 \mathrm{mM}$ & - & - & - & $>12.5 \mathrm{mM}$ & $>25 \mathrm{mM}$ & $>0.390 \mathrm{mM}$ \\
\hline D-mannose & - & - & - & - & $>6.25 \mathrm{mM}$ & - & - \\
\hline D-arabinose & - & $>25 \mathrm{mM}$ & - & - & $>12.5 \mathrm{mM}$ & $>6.25 \mathrm{mM}$ & - \\
\hline L-arabinose & - & - & - & - & $>12.5 \mathrm{mM}$ & - & - \\
\hline D-galactose & - & $>12.5 \mathrm{mM}$ & - & - & $>25 \mathrm{mM}$ & - & - \\
\hline D-fructose & - & $>6.25 \mathrm{mM}$ & - & $>3.125 \mathrm{mM}$ & $>25 \mathrm{mM}$ & $>3.125 \mathrm{mM}$ & - \\
\hline D-mannitol & - & - & - & $>0.390 \mathrm{mM}$ & $>25 \mathrm{mM}$ & $>1.562 \mathrm{mM}$ & - \\
\hline D-sucrose & - & - & $>1.562 \mathrm{mM}$ & $>25 \mathrm{mM}$ & - & $>6.25 \mathrm{mM}$ & - \\
\hline D-maltose & - & - & $>6.25 \mathrm{mM}$ & $>25 \mathrm{mM}$ & $>12.5 \mathrm{mM}$ & $>25 \mathrm{mM}$ & - \\
\hline D-lactose & - & - & - & $>50 \mathrm{mM}$ & $>6.25 \mathrm{mM}$ & $>25 \mathrm{mM}$ & - \\
\hline Melibiose & - & $>25 \mathrm{mM}$ & - & - & $>1.562 \mathrm{mM}$ & - & - \\
\hline D-trehalose dihydrate & - & - & - & $>50 \mathrm{mM}$ & $>25 \mathrm{mM}$ & $>3.125 \mathrm{mM}$ & - \\
\hline D-raffinose & - & $>50 \mathrm{mM}$ & - & - & - & $>0.781 \mathrm{mM}$ & - \\
\hline Maltotriose & - & $>12.5 \mathrm{mM}$ & - & - & - & $>50 \mathrm{mM}$ & - \\
\hline Inulin & - & - & - & $>3.906 \mu \mathrm{g} / \mathrm{ml}$ & $>125 \mu \mathrm{g} / \mathrm{ml}$ & - & - \\
\hline Pullulan & - & - & - & $>500 \mu \mathrm{g} / \mathrm{ml}$ & $>125 \mu \mathrm{g} / \mathrm{ml}$ & - & - \\
\hline Starch & - & - & - & $>31.25 \mu \mathrm{g} / \mathrm{ml}$ & $>500 \mu \mathrm{g} / \mathrm{ml}$ & - & - \\
\hline Ionositol & - & - & - & $>6.25 \mathrm{mM}$ & - & $>50 \mathrm{mM}$ & - \\
\hline Chondroitin-6-sulphate & - & - & - & $>250 \mu \mathrm{g} / \mathrm{ml}$ & $>15.62 \mu \mathrm{g} / \mathrm{ml}$ & - & - \\
\hline D-glucosamine hydrochloride & - & - & - & - & - & $>25 \mathrm{mM}$ & - \\
\hline D-galactosamine hydrochloride & - & - & - & - & - & $>25 \mathrm{mM}$ & - \\
\hline D-glucuronic acid & - & - & - & - & - & - & $>1.562 \mathrm{mM}$ \\
\hline D-galacturonic acid & $>6.25 \mathrm{mM}$ & $>12.5 \mathrm{mM}$ & - & - & - & - & $>6.25 \mathrm{mM}$ \\
\hline$N$-acetyl-D-galactosamine & - & - & - & $>25 \mathrm{mM}$ & - & - & - \\
\hline 2-Deoxy-D-glucose & - & $>12.5 \mathrm{mM}$ & - & - & $>25 \mathrm{mM}$ & $>12.5 \mathrm{mM}$ & - \\
\hline 2-Deoxy-D-ribose & - & - & - & - & $>50 \mathrm{mM}$ & - & - \\
\hline Thiogalactoside & - & - & - & - & $>250 \mu \mathrm{g} / \mathrm{ml}$ & - & - \\
\hline Bovine submaxillary mucin & - & - & - & - & $>6.25 \mu \mathrm{g} / \mathrm{ml}$ & - & - \\
\hline Porcine stomach mucin & - & $>6.25 \mu \mathrm{g} / \mathrm{ml}$ & - & - & - & $>6.25 \mu \mathrm{g} / \mathrm{ml}$ & - \\
\hline Fetuin & - & $>3.125 \mu \mathrm{g} / \mathrm{ml}$ & - & - & $>125 \mu \mathrm{g} / \mathrm{ml}$ & - & - \\
\hline Asialofetuin & - & - & - & $>7.812 \mu \mathrm{g} / \mathrm{ml}$ & $>125 \mu \mathrm{g} / \mathrm{ml}$ & - & - \\
\hline$\gamma$-globulin & - & - & - & - & - & $>6.25 \mu \mathrm{g} / \mathrm{ml}$ & - \\
\hline
\end{tabular}

-: Non-inhibitory.

Amongst various glycoproteins tested, sialoglycoproteins (bovine submaxillary mucin, porcine stomach mucin, fetuin, and asialofetuin) were found strong inhibitors for some lectin-positive cultures. Fetuin has a triantennary structure with terminal Gal $\beta 1-4 \mathrm{GlcNAc}$ and three $O$-linked structures [47]. Fetuin inhibited lectin activity of $F$. globosum and $F$. proliferatum, whereas asialofetuin a complex glycoprotein with three terminal galactose residues was reported as a potent inhibitor for both $F$. nivale and $F$. proliferatum lectins. Lectins from $F$. globosum and $F$. pseudoanthophilum has been inhibited by porcine stomach mucin, which contains traces of $\mathrm{N}$-acetyl 9-O-acetyl neuraminic 
acid, $90 \%$ (v/v) $N$-glycolyl neuraminic acid and 10\% (v/v) $N$-acetyl neuraminic acid [48]. Lectin from $F$. proliferatum was found specific to bovine submaxillary mucin (BSM). BSM comprises of $N$-acetyl neuraminic acid (NeuAc), $N$-glycolyl neuraminic acid (NeuGc), $\mathrm{N}$-acetyl 9-O-acetyl neuraminic acid and 8,9-di-O-acetyl neuraminic acid [40]. Previous investigations on Fusarium solani lectin displayed specificity for $N$-linked as well as $O$-linked glycotypes [39].

Lectins from $F$. nivale and $F$. proliferatum showed a potent affinity for chondroitin-6-sulphate, which is a sulfated glycosaminoglycan (GAG) made out of a chain of alternating sugars $(N$-acetylgalactosamine and glucuronic acid). Lectins of these two species also interacted with $N$-acetyl-D-galactosamine and thiogalactoside, respectively. $\mathrm{N}$-acetyl-D-galactosamine (Gal-NAc) which is an $\mathrm{N}$-acetyl derivative of galactose and is of extraordinary interest since they have been accounted in recognizing tumor-associated antigens (T-antigens) of malignant cells $[49,50,51]$. Due to the presence of abundant Gal-NAc on cancer cell lines, they can be exploited for cancer research and diagnosis. The exquisite saccharide specificity of Fusarium sp. lectins can be exploited for their cell-surface carbohydrate architecture.

\subsection{Influence of Enzymatic Treatment on Rabbit Erythrocytes}

The hemagglutination activity after neuraminidase treatment of rabbit erythrocytes enhanced the agglutination titre of crude extracts from $F$. globusum, F. proliferatum, $F$. pseudoanthophilum and $F$. nivale (Table 4). Universally, under physiological $\mathrm{pH}$ and ionic strength, erythrocytes carry net negative charge [52]. The negative surface charge is due to ionized sialic acid. Neuraminidase, a glycoside hydrolase enzyme adheres to the membrane glycoprotein by cleavage of O-glycosidic linkage, releases sialic acid from the membrane, alters cell interaction [53], and reduces net surface charge [54]. Rabbit erythrocytes are rich in 9-O-acetylneuraminic acid on their surface $[39,40]$ and neuraminidase treatment exposes extra galactosyl-deposits on the surface of the cell, which enhances the agglutination of rabbit blood cells [55]. These results substantiate our previous findings on lectins from Fusarium sp. [35,36].

Table 4: Effect of enzymatic modification of rabbit erythrocytes on lectin-mediated haemagglutination from Fusarium sp.

\begin{tabular}{lccc}
\multicolumn{1}{c}{ Fungal culture } & $\begin{array}{c}\text { Untreated } \\
\text { (Titre) }\end{array}$ & $\begin{array}{c}\text { Neuraminidase } \\
\text { treated (Titre) }\end{array}$ & $\begin{array}{c}\text { Protease } \\
\text { treated (Titre) }\end{array}$ \\
\hline Fusarium acutatum & 32 & 32 & 128 \\
Fusarium globosum & 8 & 32 & 4 \\
Fusarium lactis & 128 & 128 & 32 \\
Fusarium nivale & 32 & 128 & 32 \\
Fusarium proliferatum & 2 & 16 & 2 \\
Fusarium pseudoanthophilum & 16 & 128 & 32 \\
Fusarium robustum & 32 & 32 & 16 \\
\hline
\end{tabular}

${ }^{a}$ Ten day old cultures grown in liquid medium was used for the determination of lectin activity.

Protease treatment of rabbit erythrocytes has not displayed any significant effect on hemagglutination activity of Fusarium sp. except for $F$. acutatum and $F$. pseudoanthophilum (Table 4). The decline in agglutinability of rabbit erythrocytes after protease treatment exhibits the removal of favored restricting sites of Fusarium sp lectin domains [36]. In an earlier report, native and trypsinized human erythrocytes were found not susceptible to lectin from $F$. solani, but neuraminidase and pronase treated erythrocytes readily agglutinated $F$. solani lectin [38].

\subsection{Culture Age vs. Lectin Activity}

Lectin activity was resolved over a period of 5-12 days to analyze the effect of culture age on lectin expression. However, the present study explicit lectin activity in 7-8 days old cultures. Though, highest lectin activity was expressed on 9-10 days old cultures of $F$. proliferatum and $F$. pseudoanthophilium (Figure 1). None of the cultures expressed lectin activity beyond 11 days of growth. Though with progressing culture age there was an increase in biomass, there was no expansion in hemagglutination activity. This indicates that lectin activity is not a function of culture age alone. Fusarium sp. lectins were found to be developmentally regulated. The developmental regulation of Fusarium sp. lectins authenticates our prior findings on lectins from Fusarium sp. $[35,36]$ and other microfungi $[23,26]$.

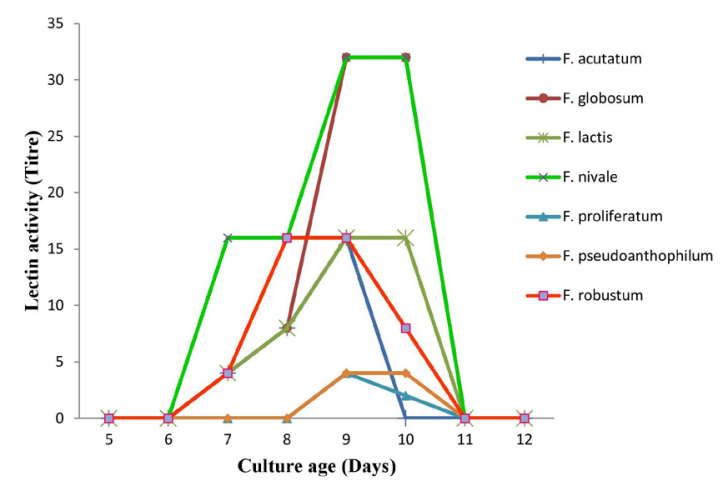

Figure 1: Effect of culture age on lectin activity of Fusarium sp.

\section{CONCLUSIONS}

It is apparent from the present investigation that Fusarium sp. portrays a diverse fountainhead of rabbit erythrocytes specific intracellular mycelial lectins. The exclusive and novel saccharide specificity profile of some of the Fusarium sp. lectins can be exploited for their quiescent role in pharmaceutics and in clinical glycobiology research. Outcomes from these new Fusarium sp. lectins would add on to the previous database of fungal lectins. In the foreseeable future, there is still a vast number of Fusarium species to be analyzed with the possibility to increase the variety of structures and specificity.

\section{REFERENCES}

1. Singh RS, Tiwary AK, Kennedy JF. Lectins: Sources, activities and applications. Critical Reviews in Biotechnology, 1999; 19:145-178.

2. Singh RS, Thakur SR, Bansal P. Algal lectins as promising biomolecules for biomedical research. Critical Reviews in Microbiology, 2015; 41:77-88.

3. Singh RS, Bhari R. 2013. Current status of microbial lectins in biomedical research. In: Singh RS, Pandey A, Larroche C, editors. Advances in industrial biotechnology, New Delhi, India: IK International Publishing House Pvt Ltd, 315-361.

4. Dan X, Liu W, Ng TB. Development and applications of lectins as biological tools in biomedical research. Medicinal Research Reviews, 2016; 36:221-247.

5. Bojarova P, Kren V. Sugared biomaterial binding lectins: Achievements and perspectives. Biomaterials Science, 2016; 4:1142-1160.

6. Tiwary AK, Singh RS. Lectins as tumor cell specific and drug targeting molecules. Research Bulletin Panjab University, 1998; 48:55-85. 
7. Tiwary AK, Singh RS. Lectins as novel drug targeting molecules. Indian Journal of Pharmaceutical Science, 1999; 61:259-267.

8. Mody R, Joshi S, Chaney W. Use of lectins as diagnostic and therapeutic tools for cancer. Journal of Pharmacological and Toxicological Methods, 1995; 33:1-10.

9. Singh RS, Kaur HP, Kanwar J. Mushroom lectins as promising anticancer substances. Current Protein and Peptide Science, 2016; 17:797-807.

10. Hashim OH, Jayapalan JJ, Lee CS. Lectins: An effective tool for screening of potential cancer biomarkers. Peer J, 2017 5:e3784.

11. Syed P, Gidwani K, Kekki H, Leivo J, Pettersson K, Lammininmaki U. Role of lectin microarrays in cancer diagnosis. Proteomics, 2016; 16:1257-1265.

12. Singh RS, Walia AK. Characteristics of lichens lectins and their role in symbiosis. Symbiosis, 2014; 62:123-134.

13. Singh RS, Walia AK. Lectins from red algae and their biomedical potential. Journal of Applied Phycology, 2018; 30:1833-1858.

14. Singh RS, Bhari R, Kaur HP. Mushrooms lectins: Current status and future perspectives. Critical Reviews in Biotechnology, 2010; 30:99126.

15. Singh RS, Bhari R, Kaur HP. Characteristics of yeast lectins and their role in cell-cell interactions. Biotechnology Advances, 2011; 29:726731.

16. Singh RS, Bhari R, Kaur HP. Current trends of lectins from microfungi. Critical Reviews in Biotechnology, 2011; 31:193-210.

17. Singh RS, Walia AK, Khattar JS, Singh DP, Kennedy JF. Cyanobacterial lectins characteristics and their role as antiviral agents. International Journal of Biological Macromolecules, 2017; 102:475-496.

18. Singh RS, Walia AK, Pratibha, Khattar JIS, Singh DP. New cell surface lectins with complex carbohydrate specificity from cyanobacteria. Indian Journal of Experimental Biology, 2017; 55:514-522.

19. Singh RS, Walia AK, Kanwar JR. Protozoa lectins and their role in host-pathogen interactions. Biotechnology Advances, 2016; 34:10181029.

20. Singh RS, Walia AK, Kanwar JR, Kennedy JF. Amoebiasis vaccine development: A snapshot on E. histolytica with emphasis on perspectives of Gal/GalNAc lectin. International Journal of Biological Macromolecules, 2016; 91:258-268.

21. Singh RS, Tiwary AK, Bhari R. Screening of Aspergillus species for occurrence of lectins and their characterization. Journal of Basic Microbiology, 2008; 48:112-117.

22. Singh RS, Bhari R, Rai J. Further screening of Aspergillus species for occurrence of lectins and their partial characterization. Journal of Basic Microbiology, 2010; 50:1-8.

23. Singh RS, Kaur HP, Singh J. New lectins from Aspergilli and their carbohydrate specificity. Biologia, 2014; 69:15-23.

24. Singh RS, Sharma S, Kaur G, Bhari R. Screening of Penicillium species for occurrence of lectins and their characterization. Journal of Basic Microbiology, 2009; 49:471-476.

25. Singh RS, Jain P, Kaur HP. Characterization and antimicrobial activity of lectins from Penicillium sp. Indian Journal of Experimental Biology, 2013; 51:984-991.

26. Singh RS, Walia AK. New mycelial lectins from penicilli with complex carbohydrate specificity. Biologia, 2016; 71:388-395.

27. Singh RS, Bhari R, Kaur R. Purification, characterization and mitogenic potential of a mucin specific lectin from Aspergillus sparsus. Applied Biochemistry and Biotechnology, 2015; 175:1938-1947.

28. Singh RS, Kaur HP, Singh J. Purification and characterization of a mycelial mucin specific lectin from Aspergillus panamensis with potent mitogenic and antibacterial activity. Process Biochemistry, 2015; 50:2251-2258.

29. Singh RS, Bhari R, Singh J, Tiwary AK. Purification and characterization of a new mucin-binding lectin from Aspergillus nidulans with potent mitogenic activity. World Journal of Microbiology and Biotechnology, 2011; 27:547-554.

30. Singh RS, Kaur HP, Singh J. Purification and characterization of a mucin specific mycelial lectin from Aspergillus gorakhpurensis: Application for mitogenic and antimicrobial activity. PLoS ONE, 2014; 9:e109265.

31. Singh RS, Walia AK, Kennedy JF. Purification and characterization of a mitogenic lectin from Penicillium duclauxii. International Journal of Biological Macromolecules, 2018; 116:426-433.

32. Singh RS, Bhari R, Rana V, Tiwary AK. Immunomodulatory and therapeutic potential of a mycelial lectin from Aspergillus nidulans. Applied Biochemistry and Biotechnology, 2011; 165:624-638.

33. Singh RS, Kaur HP, Rana V, Kennedy JF. Immunomodulatory and therapeutic potential of a mucin-specific mycelia lectin from Aspergillus panamensis. International Journal of Biological Macromolecule, 2017; 96:241-248.

34. Singh RS, Kaur HP, Kennedy JF. Modulation of immunocyte functions by a mucin-specific lectin from Aspergillus gorakhpurensis. International Journal of Biological Macromolecule, 2017; 101:172178.

35. Singh RS, Thakur S. Antimicrobial activity and carbohydrate specificity of new mycelial lectins from Fusarium sp. Biologia. 2014; 69:12951302.

36. Bhari R, Kaur B, Singh RS. Lectin activity in mycelial extracts of Fusarium species. Brazilian Journal of Microbiology, 2016; 47:775780.

37. Ishikawa F, Oishi K. Production, purification, and characterization of Neurospora sitophila lectin. Agricultural and Biological Chemistry, 1989; 53:1769-1776.

38. Khan F, Ahmad A, Khan KI. Purification and characterization of a lectin from endophytic fungus Fusarium solani having complex sugar specificity. Archives of Biochemistry and Biophysics, 2007; 457:243251.

39. Pfeil R, Kamerling JP, Kuster JM, Schauer R. O-acetylated sialic acids in erythrocyte membranes of different species. Gesellschaft Deutscher Chemiker, 1980; 361:314-315.

40. Denis M, Palatty PDM, Bai NR, Suriya SJ. Purification and characterization of a sialic acid specific lectin from the hemolymph of the freshwater crab Paratelphusa jacquemontii. European Journal of Biochemistry, 2003; 270:4348-4355.

41. Sadananda TS, Govindaappa M, Ramachandra YL. Invitro antioxidant activity of lectin from different endophytic fungi of Viscum album $L$. British Journal of Pharmaceutical Research, 2014; 4:626-643.

42. Tronchin G, Ensault K, Sanchez M, Larcher G, Leblond AM, Philippe J. Purification and partial characterization of a 32-kilodalton sialic acid specific lectin from Aspergillus fumigatus. Infection and Immunity, 2002; 70:6891-6895.

43. Chabasse D, Robert R. Detection of lectin from Chrysosporium keratinophilum (Frey) Carmichael and Anixiopsis stercoraria (Hansen) Hansen by inhibition of haemagglutination. Annales De l'Institut Pasteur. Microbiology, 1986; 137:187-193.

44. Wong J Ho, Ng TB. Isolation \& characterization of glucose/mannose/ rhamnose specific lectin from the knife bean Canavalia gladiata. Archives of Biochemistry and Biophysics, 2005; 439:91-98.

45. Kjaer TR, Le TM, Skov PJ, Sander B, Golas MM, Jensenius JC, Andersen GR, Thiel S. Structural insights into the initiating complex of the lectin pathway of complement activation. Structure, 2003; 23:342351.

46. Sadananda TS, Govindappa M, Ramachandra YL. Isolation and characterization of D-galactose, $N$-acetylgalactosamine, fructose, maltose specific lectin from eight different endophytic fungi of Viscum album L. Asian Journal of Biomedical and Pharmaceutical Science, 2013; 3:11-20.

47. Townsend RR, Hardy MR, Wong TC, Lee YC. Binding of N-linked bovine fetuin glycopeptides to isolated rabbit hepatocytes: Gal/GalNAc hepatic lectin discrimination between $\mathrm{Gal} \beta(1,4) \mathrm{GlcNAc}$ and $\mathrm{Gal} \beta(1,3)$ GlcNAc in a triantennary structure. Biochemistry, 1986; 25:5716-5725.

48. Fragkiadakis GA, Stratakis EK. The lectin from the crustacean Liocarcinus depurator recognizes $\mathrm{O}$-acetyl sialic acid. Comparative Biochemistry and Physiology, 1997; 117:545-552. 
49. Terada D, Kawai F, Noguchi H, Unzai S, Hasan I, Fujii Y, Yong Park S, Ozeki Y, Tame JRH. Crystal structure of MytiLec, a galactose-binding lectin from the mussel Mytilus galloprovincialis with cytotoxicity against certain cancer cell types. Scientific Reports, 2016; 6:28344.

50. Poiroux G, Barre A, van Damme EJM, Benoist H, Rouge P. Plant lectins targeting O-Glycans at the cell surface as tools for cancer diagnosis, prognosis and therapy. International Journal of Molecular Sciences, $2017 ; 18: 1232$

51. Hwang HJ, Han JW, Kim GH, Han JWC. Functional expression and characterization of the recombinant N-Acetyl-Glucosamine/N-AcetylGalactosamine specific marine algal lectin BPL3. Marine Drugs, 2018; 16:13.

52. Eylar EH, Madoff MA, Brody OV, Oncley JL. The contribution of sialic acid to the surface charge of the erythrocyte. Journal Biological Chemistry, 1962; 237:1992-2000.

53. Lamont JT, Isselbacher KJ. The effects of neuraminidase on Con A agglutination of erythrocytes: Evidence for adsorption of neuraminidase to erythrocyte membrane. Journal of Cellular Physiology, 1977; 90:565-572.

54. Durocher JR, Payne RC, Conrad ME. Role of sialic acid in erythrocyte survival. Blood, 1977; 45:11-20.

55. Skutelsky E, Bayer EA. Cell-type related segregation of surface galactosyl-containing components at an early development stage in hemopoietic bone marrow cells in rabbit. Journal of Cell Biology, 1983; 96:184-190.

How to cite this article:

Singh RS, Thakur SR. New Rabbit Erythrocyte Specific Mycelial Lectins from Fusarium sp. with Complex Saccharide Specificity. J App Biol Biotech. 2019;7(2):7-13. DOI: 10.7324/JABB.2019.70202 